\title{
Teaching communication at the Medical School in Ljubljana
}

\author{
Marija Petek Šter
}

Department of family medicine Medical faculty Ljubljana, Slovenia

\author{
Corresponding author: \\ Marija Petek Šter \\ Department of family medicine \\ Medical faculty Ljubljana \\ Poljanski nasip 58 \\ 1000 Ljubljana \\ Slovenia \\ marija.petek-ster@mf.uni-lj.si \\ Tel.: + 38631607752 \\ Fax: +38614386910
}

Received: 12 December 2011

Accepted: 4 January 2012

Copyright (C) 2012 by

Academy of Sciences and Arts

of Bosnia and Herzegovina.

E-mail for permission to publish:

amabih@anubih.ba

\begin{abstract}
Early clinical exposure helps medical students to develop appropriate attitudes towards their learning and future medical practice and give them an opportunity for improving communication skills. New curriculum at the Medical faculty of Ljubljana introduced early clinical exposure (ECE) for the first year medical students through the subject "Communication". We present the aims and the content of the curriculum "Communication" and present our experience, students' feedback, dilemmas and ideas for the future development of the curriculum. Decision for the introduction of this subject is based on the result of survey about the key competences of doctors, review of the literature and empirical recognition of the fact that previous programme lacked the necessary knowledge and experience for good interpersonal communication. The main goals of our teaching are in improving communication skills and understanding and assuming that good doctor-patients relationship is crucial for the successful treatment. The curriculum consists of theoretical part (lectures from medical psychology) and practical part (communication in a small group using prepared vignettes, interview with nursing home residents and observation of general practitioners' work during their 1-day practice attachment). Students evaluated the curriculum as very valuable at the beginning of their learning. The practical part of the programme, in which they had contact with patients and experienced the role of a physician, better, was highly appreciated. ECE help medical students improve their communication skills, they interact with more confidence in interaction with patients and develop appropriate personal attitudes for their future professional carrier.
\end{abstract}

Key words: Curriculum changes, Early clinical exposure, Communication, Experience, Dilemmas.

\section{Introduction}

More than thirty years ago, the first medical faculties in Europe introduced early patient contact in their curricula (1). Taking into account positive experiences, many faculties of medicine now include programmes using ear- ly clinical exposure to introduce medical students to important topic in medicine (2 - 9).

Early clinical exposure (ECE) was justified with the fact that the patient care is becoming more and more complex, but on the other hand it is clear that modern medical technology is not a replacement for profes- 
sional patient-doctor relationship. ECE is an opportunity for improving communication skills which are helpful in establishing a good doctor-patient relationship and understanding the patient as a human being.

Early experience influenced students in several ways:

- Influence their attitudes: motivate students for the study of preclinical subjects, make students more confident to meet and interview patients, help build self-awareness, including the ability to recognise and respond to feelings of uncertainty and inadequacy, helped students develop empathic response to ill patients, becoming more mature and acclimatizing to professional settings and identifying with doctor's role model (10).

- Improve the understanding of subject matter: Early experience made students more confident in their knowledge, taught them things that could not be taught from the books and made medical science more comprehensible. It also helps learn about ethical dimensions of patient care (10).

- Improve clinical skills: Early experience improved students' ability to relate to patients and communicate empathy. It helped them to understand the doctor-patient relationship and the importance of listening to patients, carers and other professionals. Students valued exploring social and psychological determinants of health and disease through contact with real patients.

Teaching enthusiastic young students can also motivate and reward teachers and patients. They confirmed that contact with enthusiastic students means for general practitioners important gain in self-esteem.

Before the changes of curriculum at Ljubljana Medical faculty in Academic year 2009/2010 the students had their first contact with patients though the subject (eng. "internistic propaedeutic") in the third year, in which students learn mainly about clinical examination. The teaching of medical psychology in the second year (and in the third year only for the students who select the subject as an option) did not offer the basic knowledge of psychological and interpersonal relationship, which are important for relationship and communication between doctor and patient. Medical students started with learning communication in the last year of their study at Medical faculty through the subject "family medicine".

Decision for the introduction of this subject is based on data from the literature, result of our own research which found out that Ljubljana Medical Faculty does not prepare students adequately for providing motivation and guidance to their patients, feeling empathy and managing team work and communication (11), and the empirical recognition of the fact that previous programme lacked the necessary knowledge and experience for good interpersonal communication.

New curriculum at the Medical faculty of Ljubljana according to Bologna declaration introduced early clinical exposure for the first year medical students through the subject "Communication".

The aim of the article is to present the subject "Communication" at Ljubljana Medical faculty and discuss about our first experiences with teaching.

\section{Methods}

\section{Aims of the curriculum}

With ECE we want to achieve several aims: provide students with the basic knowledge on medical psychology teach them how to communicate with healthy people and patients, present them the rules for communication within a small group and help them to understand that good doctor-patients relationship is crucial for the successful treatment. 


\section{Structure of the curriculum and teaching methods}

Curriculum has theoretical and practical part (Figure 1).

\section{Theoretical part}

Medical psychology means contribution of psychology to health improvement, disease prevention, recognition of risk factors and improvement of health care systems and influence of the public opinion regarding health. We teach the basics of medical psy- chology through the lectures. Students get the basic knowledge on communication and the models of communication which are used in health care through the lectures.

\section{Practical part}

Communication is the act of conveying a massage to another person, and it is an essential skill for establishing physician-patient relationship and effective functioning among health care professionals. There are different methods of teaching communication skills like: watching teachers, who

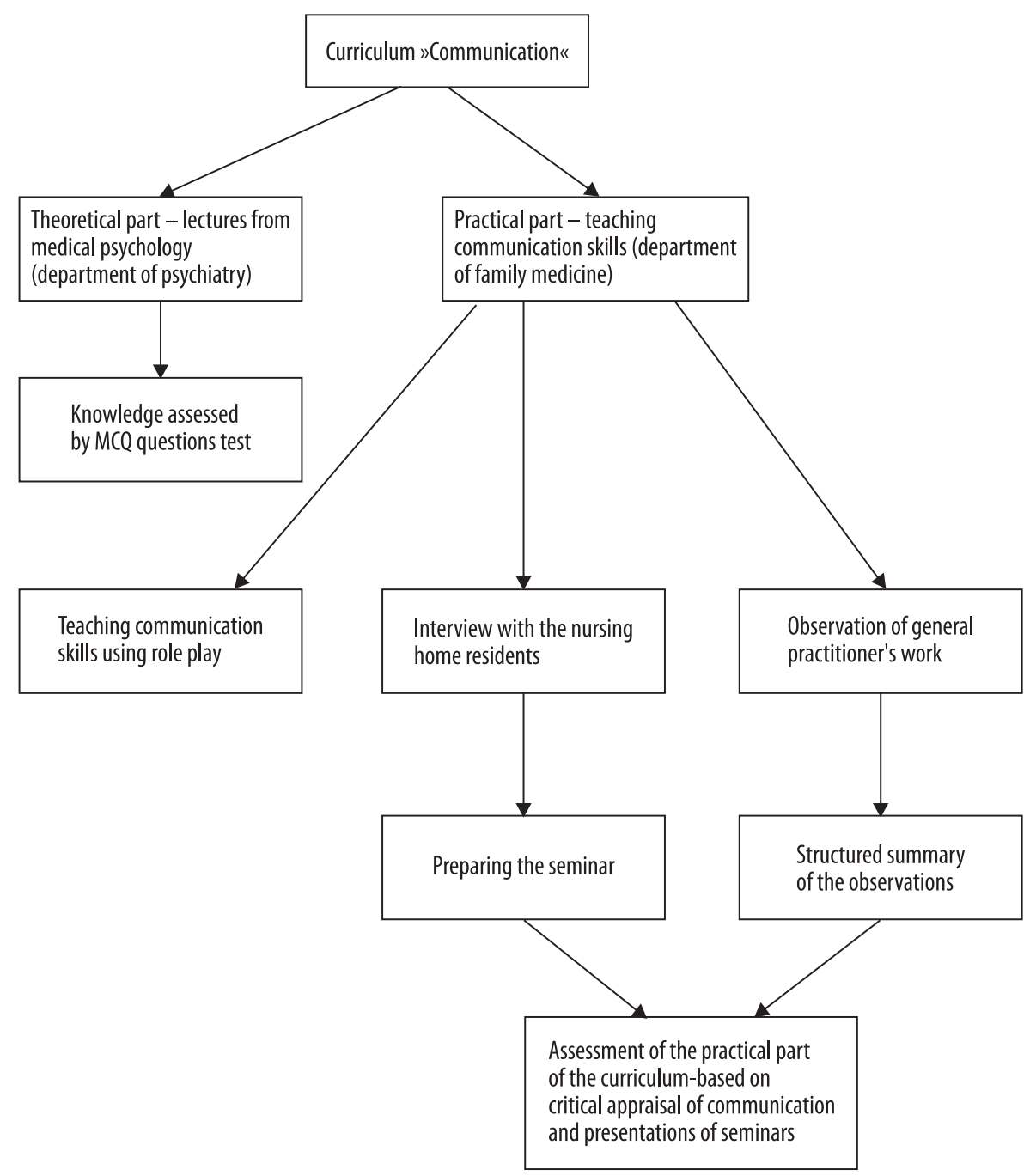

Figure 1 Structure of the curriculum 
are considered to be a role model for their learners, watching videotapes, role play, group work, standardised or simulated patients and real patients (12). We are using some of these methods in practical part of our curricula:

\section{Teaching communication skills using role play}

Practical exercises in small groups of 12 to 15 students are preparation for the field work. We used role play as a teaching method for learning communication (Role play). After the theoretical presentation of the role play and rules for giving feedback, the teacher demonstrates the method. In the next step, the students in groups of three perform role play using the prepared scenario. Two of the students are actors in the role play, and the third one is an observer. When the role play is finished, the actors and observer give feedback. Teacher has to led the discussion, taking into account also comments and suggestions of other students and summarise the main findings. Three role plays are played. Each of the students has an opportunity to be involved in a role-play as a physician, patient or as an observer. The scenarios for the role-plays were prepared the way that students don't need medical knowledge and could be emphatic with the problem (for example: drinking problems).

\section{Interview with the nursing home residents}

Nursing homes are institutions of social care and mainly offer institutional care for the elderly who are incapable of living at home due to old age, illness or other reasons. Visiting a nursing home enables students to communicate with elderly people (the average age of nursing home residents is more than 80 years) with chronic diseases, who present a model of their future patients.

Before the visit in a nursing home students became familiar with the character- istics of elderly nursing home residents and get all the necessary instructions for interviewing a nursing home resident and preparation of the seminar. Students visit a nursing home resident in pairs. One student interviews the resident, using the method of semi structured interview, the second one is an observer. When they are finished with the first interview, they go to the second resident and change their roles (the observer becomes the interviewer). An observer should observe non-verbal and verbal communication and when the interview is finished, should give oral and written feedback to the student performing an interview.

Students should follow the exact protocol for interviewing the resident. The necessary data that should be gathered are: reasons for admitting in nursing home, typical day of the nursing home resident, physical problems, psychical problems, medication, functional status and relations to relatives, staff and other residents (13). Time for semi structured interview is limited to one hour.

\section{Preparation of the seminar}

The aim of the seminar is to facilitate critical appraisal and analysis of gathering data. Students have to prepare the seminar according to the instructions (13). Seminar has to have the following subtitles:

- Presentation of gathering data,

- Analysis of the collected data: presentation of the main problems and potential solutions,

- Analysis of communication of the colleague,

- Critical appraisal: gains, feelings or fears related to the visit in nursing home

\section{Observation of general practitioner's work}

Students observe general practitioner's work during their 1-day practice attachment. The 
aim of the attachment is observation of physician's work, particularly communication between patient and general practitioner, but also communication within the team. Student should document the observation into prepared form (13) and discuss about the findings with the tutor. Based on the observation, student should prepare a short structured summary of the observations, including the following items (13):

- Who are the patients?

- What are their main problems?

- Is the same problem equally important for patient and physician?

- How did you assess physician's communication?

- What happened during the communication that should not have happened?

\section{Presentations of seminars}

At the final seminar students in small groups (12-15 students) present their seminars. Each of the students should rapport about his/her experiences with communication in nursing home and in the office. Student briefly explains the feelings during the interview, explains the communication skills (verbal and non-verbal) that were effective and identify aspects of the interview that should be done differently if they could repeat the interview. It is important that student expresses critical appraisal to her/his own communication skills and is capable to extract the main message out of the gathered data.

At the end of the presentation student should describe the reasons for fulfilling his/her expectations and expectations of the nursing home resident. In the second part of the presentation student should present the analysis of the communication of the colleague in a way to expose aspect of the interview that worked well and later on identify the aspects that could be improved. In the last part of the seminar students discuss with the teacher about their experiences from the office visit. The teacher leads the discussion in a way that stimulates comparison between communication led by the student in nursing home and communication led by general practitioners in the office.

\section{Assessment}

The assessment is integrated so that the final mark from 5 (insufficient) to 10 (excellent) consists of the mark of theoretical part (MCQ questions test) and practical part, which is based on the assessment of the seminars. Criteria for evaluation were prepared in advance. Students have to pass theoretical (60\% of points on the MCQ test) and practical part of the exam. Each part contributes $50 \%$ to the final mark.

\section{Study literature}

As a study for theoretical part of the subject (medical psychology), there are recommended readings and handouts from the lectures. For the practical part, there is a manual for exercises and seminars for students (13) and manual for teachers and tutors in the offices (14). The manual for teachers and tutors help to homogenise the teaching and assessment process.

\section{Quality assurance}

We permanently follow the quality of our teaching. During the curriculum we appreciated student's oral feedback, which is of outmost importance for future improvement of the curriculum. At the end of the curriculum we ask students to fulfil evaluation forms. Evaluation form evaluates the overall curriculum and particular parts of the curriculum using Likert scale $(1-\mathrm{bad}$ to 5 - excellent). In the last part of the evaluation form, a student may write comments, recommendations and praises regarding the content, quality and organization of curriculum. 


\section{Organisation of the curriculum and the faculty}

Curriculum is mandatory for all students of medicine and dental medicine (approximately 300 students) in the first semester at Medical faculty in Ljubljana. It is assessed with 4 ECTS credits.

Organization and teaching of the curriculum "Communication" is a result of cooperation between Department of psychiatry and Department of family medicine. There are also many external collaborators with the contract with Medical faculty helping us in the teaching process:

- Nursing home staff employed in the nursing homes in a neighbourhood of the Medical faculty,

- Primary care physicians (most of them are tutors).

\section{Results}

\section{Students' feedback}

Students collected all the necessary data without problems, although they were nervous before they started with the interview. They found their communication skills sufficient to lead the interview also in more difficult situations, like talking about sensitive topics (e.g. relationship with the family and friends) or in situations in which communication could become difficult (to talkative patent, silent patient, complicated patients).

Students appreciated the possibility for early patient contact and assessed it as of outmost importance for their personal and professional development. They found that a good relationship is important part of a treatment. They were enthusiastic about establishing empathic relationship to the elderly people. They were surprised that elderly people, who were in many times seriously ill and disabled, were so positive in their mind and they would like to share their life experiences with young people.
After the visit to an elderly person, students recognise them as more positive. They appreciated their life energy and vitality (1517). Students recognised that the main added value of the nursing home visit was the possibility for transmission of wisdom from the elderly to young.

One of our students wrote in her seminar: "Although the elderly people have many of problems, they are able to enjoy in every day. They enjoy in small things, like reading books, fulfilling the crossword puzzle or meeting and talking with the grandchildren." They said that the only thing which is important to remember is that "the small things" keep us alive.

One-day attachment in primary care was extraordinary experience for most of the students: they had an opportunity for the first time to wear white coat and had a feeling of belonging to the profession. They found physician's work as very heterogeneous and physician's responsibilities to the patients and society as the integral part of the profession. They became aware that communication skills may help improve future physicians' interaction with patients and families. Students also recognise that the way of communication should be adapted to a particular patient to enable effective and compassionate care.

Many of the students reported that experiences from one-day attachment (including all the responsibilities and dilemmas) are additional confirmation for the correctness of their decision to become a physician and improve motivation for the further study.

\section{Teachers' experiences}

Our experiences with teaching ECE are positive. We found our first year students as very enthusiastic, our teachers were keen on working very hard and patients were aware that teaching communication should be based on communication between the student and the patient. 
The organisation of the curriculum was feasible. We organised all the teaching activities in spite of high number of students and a lot of practical work taking place in different locations (nursing homes, offices) and short time (three months). Teaching of ECE was acceptable for patients involved in the teaching process. Most of the patients found ECE as important and participated in the teaching process. Based on the students' feedback and our own assessment of the fulfilling of education aims, we recognised curriculum of ECE as educationally effective: students greatly appreciate their extensive contact with patients and reported about improvement of their communication skills and empathy. In the study Joekes and co-authors found that inclusion of "professional development" teaching improve communication skills of the students in the early years of their medical course and they may benefit from further opportunities to practice basic communication skills on one to one basis with patients (18).

Tutors in the office were greeting the idea that students recognise their future profession early in the educational process at Medical faculty. One of the tutors wrote: "I was positively surprised regarding the students' enthusiasm, communication skills and bonton. I didn't expect that a first year student could be so agile, friendly and with such a discrete relationship to patients and staff. I would like to have more of students like that young colleague in my office."

There were some problems with the assessment of practical part of our subject. In spite that the assessment based on structured evaluation of seminars and reports from the office using cheque-list was prepared by our own. We were not sure that with this method we appropriately assessed communication skills.

There are different methods of assessment of communication skills (direct observation by an external observer, video or audio-taped interview rated by an independent observer, OSCE examination, patient's rating of the students performance) (19), but there were more experiences with using these methods for medical students in clinical years (20).

There are some ideas from the literature for the assessment communication skills among first year medical students like: an OSCE (21), students assess their own communication skills based on the view of their own videos (22), videotaped interview assessed by faculty using evaluation tool and patients using patient satisfaction tool (23).

\section{Discussion}

\section{Evaluation of teaching}

After two years of our teaching, we could realise that our subject was well accepted and assessed as valuable. Students appreciated the opportunity for learning interpersonal and communication skills throughout practical part of the curriculum. Most of the practical part of the curriculum took place in settings in which students could have direct contact with patients (nursing home, physician's office), that could bring to more successful teaching. $(24,25,26) \mathrm{ECE}$ was found to be important in developing establishing a good doctor-patient relationship and understanding the patient as a human being $(4,8$, $25,27)$. We believe that our students were aware that good interpersonal relationship which could be established by appropriate communication skills, are of the same importance than the clinical knowledge. Our subject could be an introduction in learning communication skills in clinical years.

\section{Dilemmas regarding ECE}

There are some dilemmas we discussed about before starting the curriculum and during our teaching process.

The first dilemma was about the personal maturity of 19 years old students. Personal 
maturity should be the limiting factor, because participating in the curriculum requires understanding and acceptance of moral and ethical norms of our profession. They confirmed that ECE enabled students to acquire professional norms and behaviour and accept responsibilities toward the patient and address the patient's needs easier. ECE also helps students in developing their own professional identity $(6,10,27)$. We discuss about ethical norms and values with students during first part of our curriculum. We were sure that students before entering clinical settings understand the basic ethical principles, especially the principle of confidentiality.

The second dilemma was that students may have the problems with establishing relationship and performing an interview with completely unknown old person. In the research of Hojat and co-authors they found that the level of empathy could be even higher in the first than in the third year (28).

The third dilemma was that the students don't know enough about the particular group of elderly people in nursing homes, their way of life and their attitudes. They found that students were not aware of process of aging and that they have sometimes negative perception regarding elderly people. On the other hand they found that with the teaching process taking place in small groups we could change negative stereotypes toward elderly people to more positive $(29,30)$.

Students had a seminar about the characteristics of elderly people, focusing on elderly nursing home residents. We also demonstrate the visit in a nursing home using the method of role play: teacher was a nursing home resident and student played his/ her own role. We believed that our students were sufficiently prepared and had positive attitudes toward elderly people and without fear of performing interview.

\section{Conclusions}

The subject "Communication", which means the introduction of ECE to the programme in Ljubljana Medical Faculty, was accepted by the students and teachers and fulfilled the aims. ECE helps medical students to develop appropriate attitudes towards their learning and future medical practice; it is an opportunity for improving communication skills and is helpful in establishing a good doctorpatient relationship and understanding the patient as a human being. It could be helpful in establishing compassionate and responsible physicians - values that are beside the clinical knowledge expected by the patients. Students of the early years of their medical course may benefit from further opportunities to practice basic communication skills on one to one basis with patients.

Acknowledgement: I would like to acknowledge to all my colleagues from the department of family medicine and department for psychiatry, especially to professor Igor Švab for his leadership and permanent support.

Conflict of interest: The author declare that she has no conflict of interest. This study was not sponsored by any external organisation.

\section{References}

1. Elestein M, Forbes JA. Early medical contact. BMJ. 1976;2(6027):97-8.

2. Larssen LC, Larsen JH, Almind G, Backer P. Medical students experience early patient contact in general practice. A descriptive and evaluation of new course in the medical curriculum. Scand J Prim Health Care. 1989;7(1):53-5.

3. Valkova L. First early patient contact for medical students in Prague. Family Practice. 1997;14(5):394-6.

4. Hampshire AJ. Providing early clinical experience in primary care. Med Educ. 1998;32(5):495-501.

5. Haffling AC, Hakansson A, Hagander B. Early patient contact in primary care: a new challenge. Med Educ. 2001;35(9):901-8.

6. Mietola J, Mantyselka P, Vaskilampi T. Doctor-patient interaction in Finish primary care 
as perceived by first year medical students. BMC Med Educ. 2005; 5:34. Available from: http://www.ncbi.nlm.nih.gov/pmc/articles/ PMC1242232/?tool=pubmed

7. Hopayian K, Howe A, Dagley V. A survey of UK medical school's arrangements for early patient contact. Med Teach. 2007;29(8):806-13.

8. Von Below B, Helquist G, Rodjer S, Gunnarsson R, Bjorkelund C, Wahlqvist M. Medical students' and facilitators' experiences of an Early Professional Contact course: Active and motivated students, strained facilitators. BMC Med Educ. 2008: 8:56. Available from: http://www.ncbi.nlm.nih. gov/pmc/articles/PMC2614986/pdf/1472-69208-56.pdf.

9. Basak O, Yaphe J, Spiegel W, Wilm S, Carelli F, Metsemakers JF. Early clinical exposure in medical curricula across Europe: an overview. Eur J Gen Pract. 2009;15(1):4-10.

10. Littelwood S, Ypinazar V, Margolis SA, Scherpbier A, Spencer J, Dornan T. Early practical experience and the social responsiveness in clinical education: systematic review. BMJ. 2005;331(7513):387-91.

11. Pavlin S, Švab I, Kovačič H. Identification and development of key competences of doctors as a starting point for modernizing the educational programme. Slo J Public Health. 2008;47(2):106-16.

12. Odhayani AA, Ratnapalan S. Teaching communication skills. Can Fam Physician 2011;57(10):1216-18.

13. Švab I, Petek Šter M. Sporazumevanje: navodila za vaje in seminar: študijsko leto 2010/2011. 1. izd. Ljubljana: Združenje zdravnikov družinske medicine, 2010. Available from: http://www.mf.uni-lj. si/kdm/1091-gradiva. (In Slovene)

14. Švab I, Petek Šter M. Sporazumevanje: navodila za vodje vaj in seminarjev: študijsko leto 2010/2011. 1. izd. (CD-ROM). Ljubljana: Združenje zdravnikov družinske medicine, 2010. (In Slovene)

15. Woolliscroft JO, Calhoun JG, Maxim BR, Wolf FM. Medical education in facitilies for the elderly. Impact on medical students, facility staff, and residents. JAMA. 1984;252(24):3382-5.

16. Arnold L, Shue CK, Jones D. Implementation of geriatric education into the first and second year of a baccalaureate-MD degree program. Acad Med. 2002;77(9):933-4.

17. Mullen K, Nicolson M, Cotton P. Improving medical students' attitudes towards the chronic sick: a role for social science research. BMC Med Educ. 2010;10:84. Available from: http://www.ncbi.nlm.nih.gov/pmc/articles/ PMC2995790/?tool=pubmed

18. Joekes K, Noble LM, Kubacki AM, Potts HW, Lyoyd M. Does the inclusion of "professional de- velopment" teaching improve medical students' communication skills? BMC Educ. 2011;11:41. Available from: http://www.ncbi.nlm.nih.gov/ pmc/articles/PMC3141797/?tool=pubmed

19. Yedidia MJ, Gillenspeie CC, Kachur E, Schwarrtz $\mathrm{MD}$, Ockene J, Chepaitis AE, et al. Effect of communications training on medical students performance. JAMA. 2003;290(9):1157-65.

20. Hodges B, Mclloroy JH. Analytic global OSCE rating is sensitive to level of training. Med Educ. 2003;37(11):1012-16.

21. Fischbeck S, Mauch M, Leschnik E, Beutel ME, Laubach W. Assessment of communication Skills with an OSCE among firs year medical students. Psychother Psychosom Med Psychol. 2011;61(11):465-71.

22. Zick A, Granier M, Makoul G. First-year medical students' assessment of their own communication skills: A video-based, open-ended approach. Pat Educ Couns. 2007;68(2):161-6.

23. Makoul G, Krupat E, Chang CH. Measuring patient views if the physician communication skills: a development and testing of the Communication Assessment Tool. Patient Educ Couns. 2007;67(3):333-42.

24. Arnold L, Shue CK, Jones D. Implementation of geriatric education into the first and second year of a baccalaureate-MD degree program. Acad Med. 2002;77(9):933-4.

25. Turan S, Elcin M, Odabasi O, Sayek I, Senemoglu N. The impact of clinical visit on communication skills training. Patient Educ Couns. 2009;77(1):42-7.

26. Bell K, Boshunizen HP, Scherpbier A, Dornan T. When only the real things will do: junior medical students' learning from real patients. Med Educ. 2009;43(11):1036-43.

27. Dornan T, Littlewood S, Margolis SA, Scherpbier A, Spencer J, Ypinazar V. How can experience in clinical and community settings contribute to early medical education? A BEME systematic review. Med Teach. 2006;28(1): 3-18.

28. G Hojat M, Vergare MJ, Maxwell, K, Brainard, Herrine SK, Isenberg GA, et al. The devil in the third year: a longitudinal study of erosion of empathy in medical school. Acad Med. 2009;84(9):1182-91.

29. Varkey P, Chutka DS, Lesnick TG. The aging game: improving medical students' attitudes toward caring for the elderly. J Am Med Dir Assoc. 2006;7(4):224-9.

30. Sahin H, Akyol AD. Evaluation of nursing and medical students' attitudes towards people with disabilities. J Clin Nurse. 2010;19(15-16):2271-9. 